\title{
ANALYSIS OF THE MAIN COMPONENTS OF HEALTH SPENDING IN THE WAEMU AREA: THE ROLE OF GOVERNMENT SPENDING
}

\author{
Foungnigue Noe COULIBALY \\ Doctor - Economist / Lecturer and Researcher, Alassane Ouattara-Bouake University, Côte d'Ivoire. \\ DOI: 10.46609/IJSSER.2021.v06i07.007 URL: https://doi.org/10.46609/IJSSER.2021.v06i07.007
}

\begin{abstract}
The aim of this study is to analyze the main components of health spending in the WAEMU area. Estimates, using a Principal Component Analysis (PCA) method, reveal that government spending comes second after external spending on health. In terms of scores on a scale of 100, government expenditure on health is 79.99 behind external expenditure on health with 80.92 as a score. However, private health expenditure should not be neglected, i.e. 65.19 out of 100 . Thus, the authorities could adopt a certain number of policies, including budget reframing, strengthening performance criteria for the management of health resources, and signing agreements for the joint supply of care in quantity and quality in order to provide to the health needs of populations.
\end{abstract}

Keywords: health expenditure, government expenditure, principal component analysis, WAEMU

\section{Introduction}

Health spending is growing even more sharply, for various reasons, both in terms of supply and demand for care. From the point of view of healthcare producers (public body, nursing staff, etc.), spending on equipment, pandemic prevention and training would be the basis of this increase. On the other hand, according to the consumer (health care applicants: patients), bad governance (corruption, political instability, etc.), the poor distribution of resources to health are all reasons which would justify these exorbitant amounts allocated to the health sector without however managing to satisfy the citizen, Jean Brignon Camal Gallouj, (2011). By the way, what about the aggregates of health spending in the WAEMU area?

Indicators of health expenditure include so-called reimbursable expenditure (or public expenditure) and non-reimbursable expenditure. These are those financed by the State or by the TFPs (Technical and Financial Partners), that is to say public expenditure, which constitutes the largest part of total health expenditure. Coulibaly, (2018). 
International Journal of Social Science and Economic Research

ISSN: 2455-8834

Volume:06, Issue:07 "July 2021"

The problem with this study lies in the fact that the developing countries, which have several sources of financing for their health system, remain those whose health situation is one of the most catastrophic in the world. In fact, the epidemiological profile of the WAEMU countries is contrasted insofar as the control of maternal mortality and the prevalence of HIV is struggling to be achieved notwithstanding the high level of health expenditure, which has fallen from 5.06 percent in 2000 to 5.60 percent in 2020; WDI and WHO, (2020).

Therefore, what are the main sources of funding for health spending in WAEMU countries? In other words, what is made up of health expenditure in the WAEMU area? What is the share of government spending in health spending?

\section{Objectives and Assumptions}

In this article, our aim is to analyze the main components of health spending in the WAEMU area. More specifically, we will: (i) analyze the composition of health expenditure in WAEMU countries, (ii) assess the share of government expenditure in health expenditure.

We formulate three (03) hypotheses which are related to the specific objectives, namely: (i) Health expenditure in WAEMU countries is of two (02) types: reimbursable expenditure (public) and non-reimbursable expenditure (private); (ii) government spending ranks second in health spending, after that of Technical and Financial Partners.

\section{Characteristics of health and government spending in the WAEMU area.}

Health expenditure indicators are formed from reorganized data from the World Bank. In addition, it should be noted that public spending on health include not only those of foreign partners, but also those of States or governments. While unreimbursed expenses include those of households and social organizations. However, these expenditures are intended respectively for demand (private health expenditure) and supply (public health expenditure); it is the latter that interest us in this article.

\subsection{Expenses not reimbursed: expenses of households and social organizations}

Given the low share of private health expenditure in the Gross Domestic Product (GDP) of countries of the union, it is clear that households and social organizations remain the only ones to finance a greater proportion of health care than medical acts (consultations, hospitalizations, surgeries, obstetrics, etc.) as well as pharmaceutical products. However, we find relevant to group all these expenses under the title private health expenditure.

\subsection{Expenses reimbursed: expenses of the rest of the world and governments}


International Journal of Social Science and Economic Research

ISSN: 2455-8834

Volume:06, Issue:07 "July 2021"

Although combined with countries' public health expenditure, the health expenditure of the rest of the world are sometimes higher than those of governments for certain countries, namely Guinea-Bissau over the entire study period, as well as Mali by the year 2013, certainly because of the socio-political instability with the advent of groups Shebab terrorists, Boko Haram or AlQaeda in the Islamic Maghreb (AQIM) and An-sardine.

On the other hand, in the six (06) other countries that are Benin, Burkina-Faso, Côte d'Ivoire, Niger, Senegal and Togo the efforts of governments in the domain of health largely exceed those of foreign partners. In view of these supranational disparities, we have preferred to keep the composite variable, that of public health expenditure combining both government expenditure and the rest of the world. Coulibaly, (2018, pp 80-82).

\subsection{Analysis of the healthcare offer}

According to literature, the supply of health care is the responsibility of the care producer, in particular: the medical profession (doctors, midwives, nurses, etc.) and administrative and health personnel. In addition, supply is sometimes subject to an "inducing effect on demand".

Indeed, health professionals as prescribers are also at the base of the demand for patient care, in the sense that for diagnostic concerns prescribe a set of medical acts thus inducing a demand. However, econometrics finds it difficult to show this inducing effect in a decisive way. Nevertheless, there is work related to cost-benefit (cost-benefit, cost-effectiveness, and costutility) methods Gutton, (1988).

\section{Methodological approach}

\subsection{Model used}

\subsubsection{Principal component analysis}

Component analysis combines descriptive techniques that apply to large data tables. It is used to highlight relationships between variables in order to reduce the dimension of the problem, that is to say the number of variables used to describe a phenomenon (Cahuzac and Bontemps, 2008).

Component analysis can be broken down into two main branches, grouping together factor analysis methods and classification methods. Within factor analysis, we group together principal component analysis (PCA) techniques, applying to tables of quantitative variables, or multidimensional scaling (MDS) generalizing it to discrete variables, factor analysis of correspondences (AFC) and its multiple extension (AFCM). 
International Journal of Social Science and Economic Research

ISSN: 2455-8834

Volume:06, Issue:07 "July 2021"

Principal component analysis, introduced in 1901 by Pearson, then developed by Hotelling in 1933 , is the oldest technique. It is only applied to quantitative variables. The principle of PCA consists in highlighting strong linear relationships between the variables studied.

In addition, PCA not only allows you to make a selection of the principal components linked to each index, but also to build the index from the principal components. Indeed, it first allows us to indicate the contribution share of government health expenditure in total health expenditure. And second, to build composite indexes of reimbursable and non-reimbursable health expenditure from the study data.

\subsubsection{Model specification}

First Step: We launch the "pca" command with all the variables concerned, then we launch the "estat kmo" command, to see if the variables contribute to the variability of the PCA estimate, if the kmo of a variable is $<0.6$ we exclude the variable from the PCA, and so on.

Repeat the operation for the remaining variables to make sure that the new situation is correct. The $50 \%$ threshold is applied by some.

Finally, the proper value of the variable must be greater than 0.30 in absolute value, for the component; the latter condition allows us to create a solid score from a single component.

After having determined the variables that can be retained in the PCA, we always calculate the PCA with the 'pca' command.

Second step: We then run the command "screeplot, yline (1)" to determine the components to be retained, If the "screeplot" of the component is $>1$, we retain it, otherwise we reject it. We can however retain the components whose 'screeplot" is more than 0.9 , To view the components (02) we launch the command "loadingplot, xline (0) yline (0)", If we have more than 02 components (axis), we can represent the axes two by two on a graph combined with the command next: "loadingplot, factors (n) combined xline (0) yline (0)".

After choosing the components, we provide an explanation (or a name) for each component, using the following procedure: This involves identifying the variables that contribute the most to each main component. To do this, we must calculate the square of each eigenvalue column. The variables that best explain the component are those with the highest squared proper values. We can retain the one which explains more than approximately $70 \%$ of the component (It should be noted that the sum of the values proper to the square is approximately 1 ).

\subsection{Study data}


The data in our study come on the one hand from documentary reviews (WHO and PNDS reports) and from WHO and World Bank databases.

The reports were used to analyze the health situation in WAEMU countries. Indeed, these reports allow us to present the overall epidemiological profile, to make a precise diagnosis of the key factors in the demand for and supply of care in the WAEMU area.

For the calculation of budgetary shares (government expenditure) in total expenditure, we use the databases of the WHO and the World Bank. The statistical tool used is STATA.14. It is used respectively to perform principal component analysis (PCA) of health expenditure.

\subsection{Results and discussions}

\subsubsection{Variable specification}

Table1: Descriptive statistics

\begin{tabular}{|c|c|c|c|c|c|}
\hline Variables & Observations & Averages & $\begin{array}{l}\text { Standard } \\
\text { deviation }\end{array}$ & Minimum & Maximum \\
\hline $\begin{array}{l}\text { Private health expenditure in \% } \\
\text { of current expenses }\end{array}$ & 168 & 56.73972 & 13.10961 & 29.57488 & 83.63081 \\
\hline $\begin{array}{c}\text { Household health expenditure in } \\
\% \text { of current expenses }\end{array}$ & 168 & 50.13774 & 11.68613 & 27.39347 & 74.72361 \\
\hline $\begin{array}{c}\text { General Government health } \\
\text { expenditure in \% of current } \\
\text { expenses }\end{array}$ & 168 & 7.767498 & 10.49583 & 0.3924876 & 43.30193 \\
\hline $\begin{array}{c}\text { External health expenditure in } \\
\% \text { of current expenses }\end{array}$ & 168 & 18.26363 & 9.405093 & 2.149728 & 48.49663 \\
\hline $\begin{array}{l}\text { Current health expenditure in \% } \\
\text { of GDP }\end{array}$ & 168 & 5.348288 & 1.437227 & 3.248984 & 9.488553 \\
\hline
\end{tabular}

Source: Author, from WDI, OMS \& TI data, 2020; Stata 14

The analysis of Table 1 reveals current expenditure in the order of $5.348 \%$ of the budgetary shares allocated to health, which represents one third of the $15 \%$ of the GDP provided for by the Abuja agreements in 2001. In addition, let us note that government health expenditure is $7.767 \%$ of current health expenditure behind external expenditure (18.264\%) and household expenditure $(50.138 \%)$.

However, it must be recognized that it is those of the State or the government and outside that determine the health supply in general, in particular: mosquito nets, hospital beds, the training of doctors, nurses and midwives according to Coulibaly, (2018). 
International Journal of Social Science and Economic Research

ISSN: 2455-8834

Volume:06, Issue:07 "July 2021"

3.3.2 Analysis of the Principal Components (PCA) of health expenditure in the WAEMU area.

Table 1 :ACP Analysis

\begin{tabular}{lc}
\hline \hline Variables & Kmo score \\
\hline \hline Private health expenditure in \% of current expenses & 0.6451 \\
Household health expenditure in \% of current expenses & 0.6516 \\
General Government health expenditure in \% of current expenses & 0.7999 \\
External health expenditure in \% of current expenses & 0.8092 \\
Current health expenditure in \% of GDP & 0.2263 \\
Total & 0.6772 \\
\hline \hline
\end{tabular}

Source: Author, from WDI, OMS \& TI data, 2020; Stata 14

This analysis clearly shows that reimbursable health expenditure occupies the first two places of total health expenditure with: external expenditure occupying the first place in current health expenditure ( 0.8092 or $80.92 \%)$.

Then we have government spending on health, which comes in second with 79.99\%. Also, private health expenditure and that of households which, constituting unreimbursed health expenditure, are not negligible, because they are of the respective order of 0.6451 , i.e. $64.51 \%$ and 0.6516 , i.e. $65.16 \%$.

Graph1: Selection of the main components

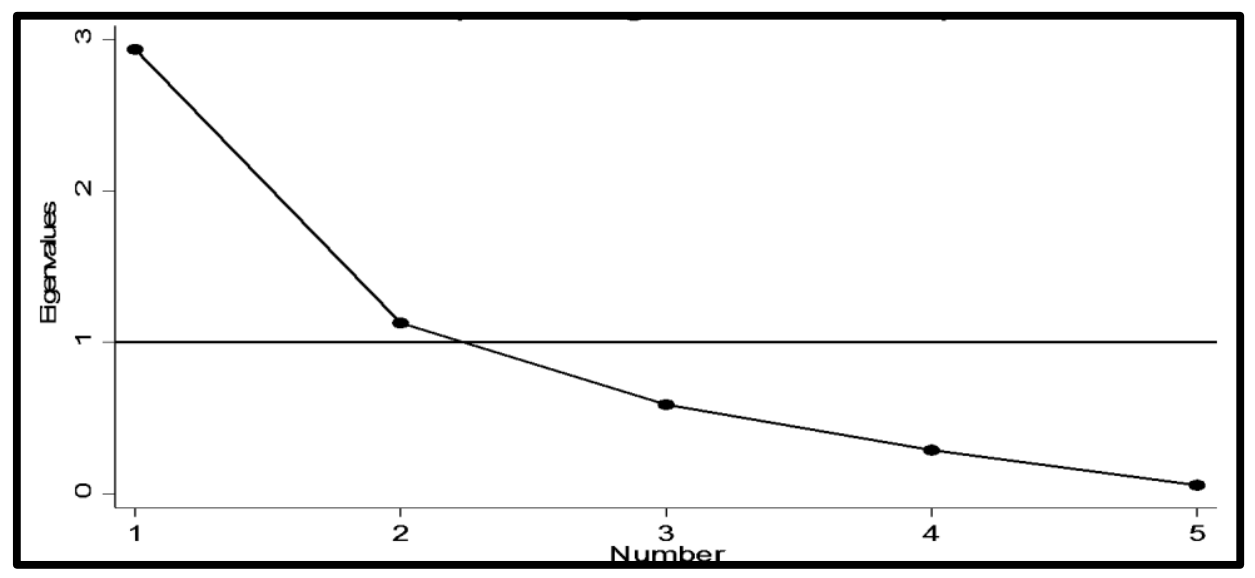

Source: Author, from WDI, OMS \& TI data, 2020; Stata 14 
In accordance with the STATA rule, which consists in retaining the factors having an "Eigenvalue" greater than 1; it therefore comes down to choosing the variables: External expenditure on health and General government expenditure on health. Thus, we can affirm that government spending ranks second in health spending in the WAEMU area; and that total health expenditure is of two types: reimbursable (external health and government health expenditure) and non-reimbursable (private health and household expenditure). This analysis then confirms our hypotheses 1 and 2.

\section{Graph 2: Breakdown of principal components}

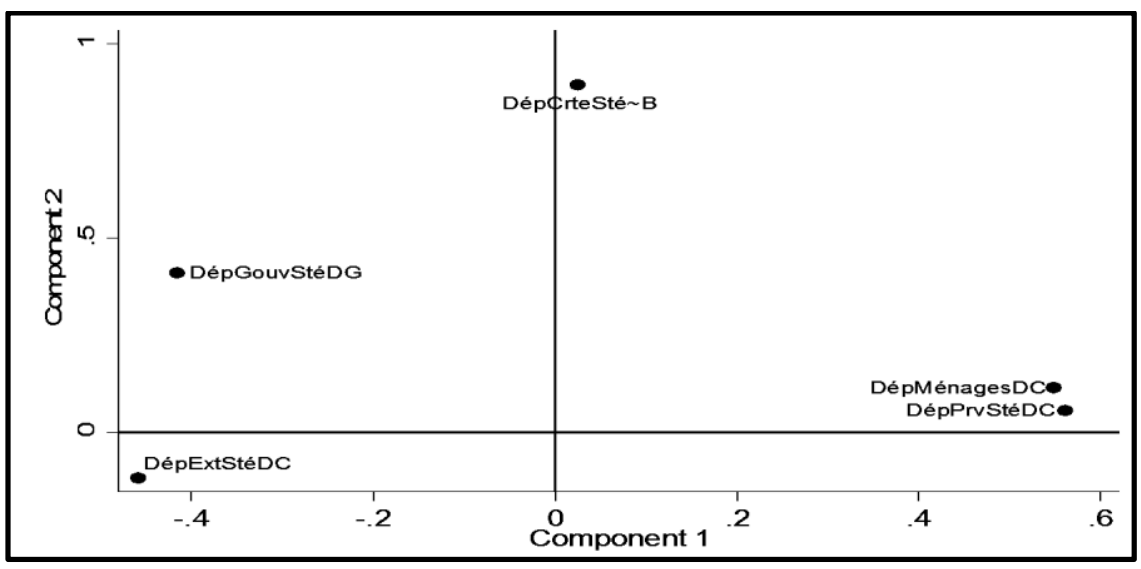

Source: Author, from WDI, OMS \& TI data, 2020; Stata 14

The analysis of this graph shows us that the first component of health expenditure is: External health expenditure since it is separated from the four (04) other variables, and remains the closest to the origin. Next, government spending on health takes second place; it remains closest to the origin as a result of external health expenditure.

\section{Conclusion}

Throughout this article, the aim is to show the place of government health expenditure in total health expenditure in the WAEMU area. In doing so, we have mobilized a review of the literature according to which the health care supply is essentially the action of States, in particular: infrastructures (hospital beds, ambulances, laboratories, etc.), and nursing and administrative staff. (doctors, midwives, nurses, community workers, etc.).

Then, using the two (02) step PCA method, we analyze the scores of the main health components, then graphically list them according to their order of arrangements in a frame. Under the main health components, two (02) main expenditures occupy the first places, unlike 
International Journal of Social Science and Economic Research

ISSN: 2455-8834

Volume:06, Issue:07 "July 2021"

the descriptive analysis which places private and household health expenditure before external and government health expenditure.

From these results, it emerges that public health expenditure (external and government health expenditure) is the main expenditure on health care. In fact, States spend excessively on health, thus posing the issue of governance and management of the latter.

Therefore, our countries must reframe the budgetary shares allocated to the health sector, adopt performance criteria in the management of health resources; which could reduce the pockets of household spending. Also, the authorities could sign agreements between the public and private sectors in order to mutually meet the health needs of the populations.

\section{Acknowledgment}

We cannot end this study without sending a sincere thank you to my fellow Doctors of the Laboratory of Analysis and Modeling of Economic Policies (LAMPE).

Our thanks also go to our colleagues at Alassane Ouattara-Bouaké University, to Professors ANASSE Anassé Adja Augustin, TIEHI Tito Nestor.

Finally, to my deceased, Father Lénissongui COULIBALY, Brother COULIBALY Samuel and COULIBALY Jacob, and Sister COULIBALY Rachel; for their unfailing support, particularly financial, moral and spiritual.

\section{Abbreviations and Acronyms:}

ACP: Principal Components Analysis

AFC: Analysis of Factorial Components

AFCM: Analysis of Factorial Multiple Components

AQIM: Al-Qaeda in the Islamic Maghreb

HIV: Human Immuno Deficiency Virus

MDS: Multidimentional Scaling

TFP: Technical and Financial Partners

TI: Transparaty Indicator

WAEMU: West African States Economic and Monetary Union 
WHO: World Health Organization

\section{Bibliography}

[1] Cahuzac, E., \& Bontemps, C. (2008). Stata par la pratique : statistiques, graphiques et éléments de programmation. Stata Press.

[2] Coulibaly F. N, (2018), «Efficacité des dépenses publiques de sante dans l'espace UEMOA », Thèse doctorale, soutenue le 27/08/2018 à l'Université Alassane Ouattara-Bouaké,

[3] Gutton H, (1988), «La santé et le marché », santé de l'économie et économie de la santé, Revue perspective $\mathrm{n}^{\circ} 47 / 48$

[4] Hotelling, H. (1933). Analysis of a complex of statistical variables into principal components. Journal of educational psychology, 24(6), 417.

[5] Hotelling, H., \& Secrist, R. D. H. (1933). The Triumph of Mediocrity in Business. Journal of the American Statistical Association, 28(184), 463-465.

[6] Jean Brignon Camal Gallouj, (2011). Précis de santé publique etd'économie de la santé, 2ème Edition Lamare

[7] Pearson, K. (1901). Principal components analysis. The London, Edinburgh and Dublin Philosophical Magazine and Journal, 6(2), 566.

[8] WHO (World Health Organization), (2020). Statistical Information System (WHOSIS).

[9] World Bank, (2020). Worldwide Governance Indicators 2020. 